\title{
A three-level hybrid metal/in-plane-CFRP/crossed-lamellar microstructure concept for containment applications
}

\author{
R. Häsäa,*, S. T. Pinho ${ }^{\mathrm{a}}$ \\ ${ }^{a}$ Department of Aeronautics, Imperial College London, South Kensington Campus, London SW7 \\ 2AZ, United Kingdom
}

\begin{abstract}
This paper proposes a novel hybrid metal/Carbon Fibre Reinforced Polymer (CFRP) microstructure which includes a bio-mimetic crossed-lamellar CFRP layer (with out-ofplane fibres) as well as traditional CFRP layers (with in-plane fibres). We show that this microstructure is capable of preserving its structural integrity due to the crossedlamellar and metal layers while the in-plane fibres provides it stiffness and strength. We studied numerically and experimentally a metal hybrid/crossed lamellar block in isolation, both with aluminium and titanium for the metal. We then proceeded to create the full microstructure, including a quasi-isotropic block. Our results show that these structures can withstand very large curvatures in a pseudo-ductile way. This makes them attractive for engineering applications where structural integrity is paramount, such as for containment structures.
\end{abstract}

Keywords: Hybrid (A), Damage tolerance (B), Microstructures (B), Pseudo-ductility

\section{Introduction}

Despite being light, stiff and strong, CFRPs are inherently brittle and fail catastrophically. As a consequence, components made of CFRP tend to separate into several parts during damage growth or allow penetration during impact. In this paper, we will refer to this separation as a loss of structural integrity.

\footnotetext{
${ }^{*}$ Corresponding author

Email address: r.hasa15@imperial.ac.uk (R. Häsä)
} 
Natural composites, such as bone and mollusc shells, have proven an attractive source of inspiration for new microstructures, as they typically retain their structural integrity despite their weak and brittle main constituents [1].

An example of such natural composite is the Strombus gigas shell (Figure 1(a)) that

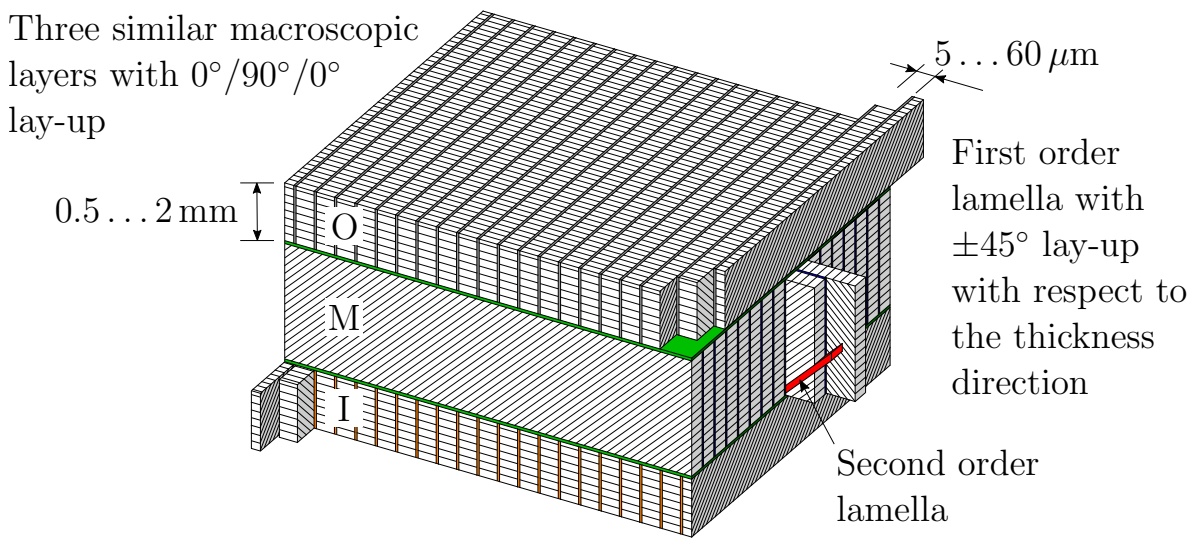

(a)

(b)

Figure 1: (a) The Strombus gigas shell (reprinted with permission from Su et al. [8], copyright 2004 American Chemical Society) has (b) a crossed-lamellar microstructure (not to scale) [9]. 
shell concludes that the main contribution to the improved toughness arises from the

macroscopic middle layer [3].

Previous research into CFRPs with crossed-lamellar microstructures $[9,11]$ has shown that the damage mechanisms of the natural composite can be reproduced in CFRP, and that the damage diffusion can be further enhanced with a microstructure that has inner and outer layers made of a ductile material.

While damage diffusion in the CFRPs with crossed-lamellar microstructures was shown to be potentially excellent [9], crossed-lamellar microstructures have no fibres in the direction of loading, which limits their use in practical engineering applications. Therefore, in this work, for the first time in the literature, we propose a hybrid metal/CFRP composite with in-plane fibres and a bio-inspired crossed-lamellar layer, and demonstrate that this novel microstructure preserves its structural integrity during failure while the in-plane fibres provide it stiffness and strength. This has significant implications for the use of hybrid composites in containment structures (e.g. for blast, containment, and for blade-off events).

\section{Methods}

\subsection{Microstructure definition}

We conceived a hybrid metal/crossed-lamellar microstructure with quasi-isotropic layers (denoted as H/CL/QI and illustrated in Figure 2) with two different materials for the metal skins (2024-T3 aluminium and Grade 2 titanium) and with the dimensions of the configurations given in Table 1. The metals were chosen based on their attractive material properties (see Table 3) and their prevalence in other fibre metal laminates [12], and the thickness was determined by the thinnest possible sheet available for each metal. The different configurations with the aluminium and titanium skins will be referred to as $\mathrm{H} / \mathrm{CL} / \mathrm{QI}-\mathrm{Al}$ and $\mathrm{H} / \mathrm{CL} / \mathrm{QI}-\mathrm{Ti}$, respectively, in the rest of this text.

The H/CL/QI microstructure comprises a hybrid metal/crossed-lamellar (H/CL) unit (Figure 2) sandwiched between two hybrid metal/quasi-isotropic (H/QI) units (Figure 2). The H/CL unit has a CFRP layer with a $\pm 45^{\circ}$ orientation with respect 


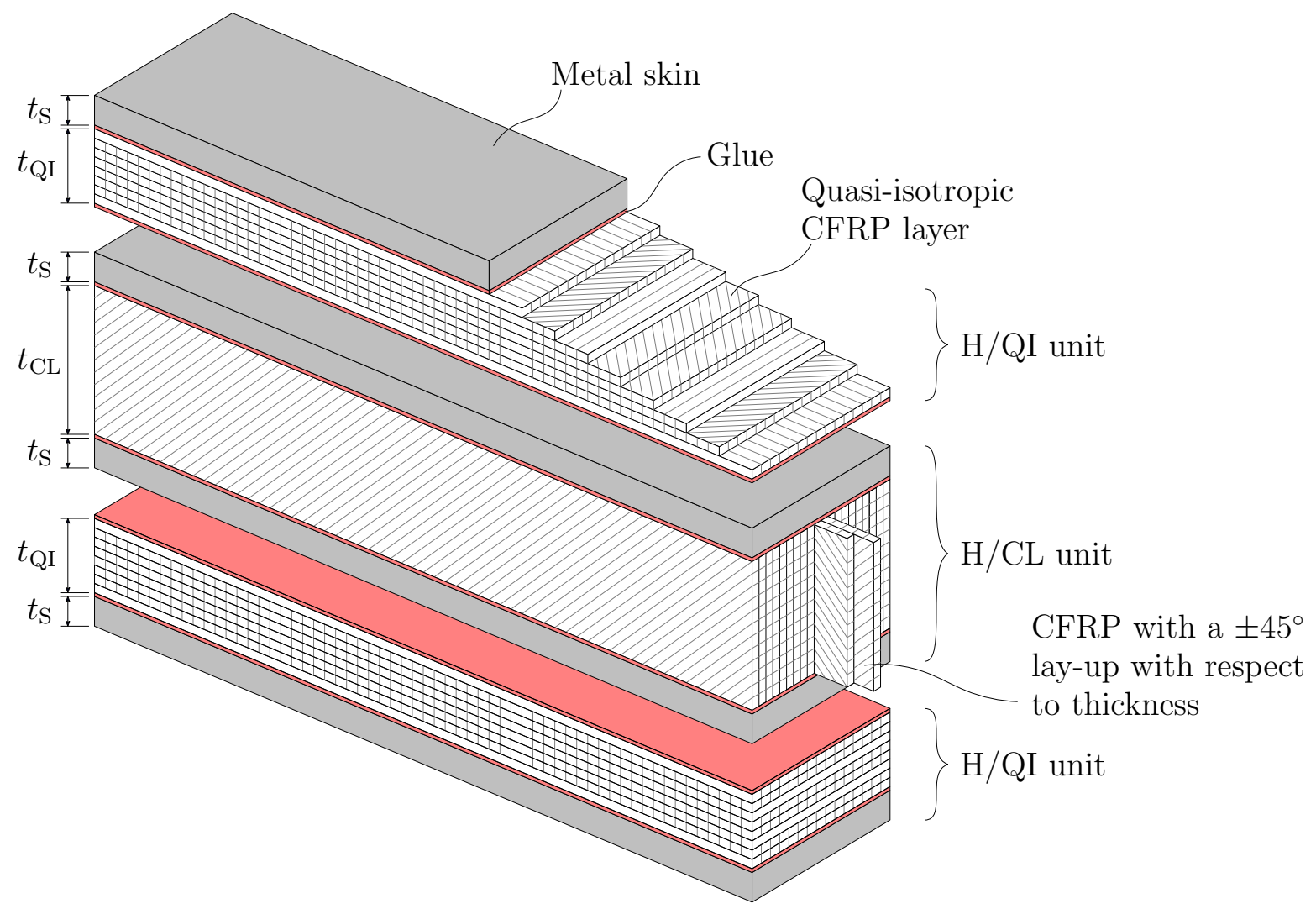

Figure 2: The H/CL/QI microstructure consists of two H/QI units and one H/CL unit.

Table 1: Dimensions of the microstructures to be prototyped.

\begin{tabular}{cccc}
\hline Configuration & $t_{\mathrm{S}}[\mathrm{mm}]$ & $t_{\mathrm{CL}}[\mathrm{mm}]$ & $t_{\mathrm{QI}}[\mathrm{mm}]$ \\
\hline $\mathrm{H} / \mathrm{CL} / \mathrm{QI}-\mathrm{Al}$ & 0.40 & 2 & 1 \\
$\mathrm{H} / \mathrm{CL} / \mathrm{QI}-\mathrm{Ti}$ & 0.05 & 2 & 1 \\
\hline
\end{tabular}

to thickness between two metal sheets. The H/QI unit consists of a quasi-isotropic sub-laminate and a sheet of metal. IM7/8552 prepreg was used for the CFRP parts of the microstructure.

The mechanical response of quasi-isotropic CFRP configurations has been extensively studied in the literature over the last decades, both numerically and experimentally (see Kaddour and Hinton [13, 14] for a benchmark of several theories). It is therefore 'relatively' well understood. Similar arguments can be made for standard hybrid metal/fibre-reinforced polymer laminates, as they are currently contained in various 
engineering components (e.g. GLARE). Therefore, within our proposed microstructure (Figure 2), the least well understood component is the H/CL unit. It is also a crucial unit in this microstructure, as it is responsible for preserving structural integrity under bending. Therefore, in this work, we will also study this unit individually, both numerically and experimentally.

\subsection{Numerical simulations of the $H / C L$ unit}

\subsubsection{The model geometry and failure mechanisms}

The mechanical behaviour of the H/CL unit is complex and not very well known. We therefore created a unit cell FE model (Figure 3) to study damage diffusion in this unit in order to evaluate whether it is feasible to prototype the microstructures with the dimensions proposed in Table 1. The FE model (Figure 3) exploits various symmetries and periodicities of the microstructure and of the damage itself, as detailed later in this section.

In the model, we included the possibility for discrete splits (i.e., cracks along the fibre direction) to grow in the middle layer and studied the mechanical response with different prescribed crack densities. Referring to Figure 3, there are two splits in the middle layer that reach the interface with the bottom layer (in the $+45^{\circ}$ and $-45^{\circ}$ plies on the left and right hand sides of the model, respectively). The horizontal distance between each split is thus $L$. As a result, we defined our chosen measure of crack density as $\eta=1 / L$. The model therefore allows us to model any crack density, and lower crack densities require wider models.

The possible locations for splits were modelled using cohesive elements with thickness $t_{\mathrm{C}}$ (Table 2) with a quadratic stress initiation criterion and linear softening. Modelling of the splits as described with a hexahedral mesh (with the mesh aligned with the splits) would typically lead to the need for tetrahedral elements at the left and right faces of the crossed-lamellar part of the model. Using tetrahedral elements at the edges could create some minor stress concentrations due to the numerical integration, but these can be avoided easily by using a zigzag shape for the boundaries and using suitable 

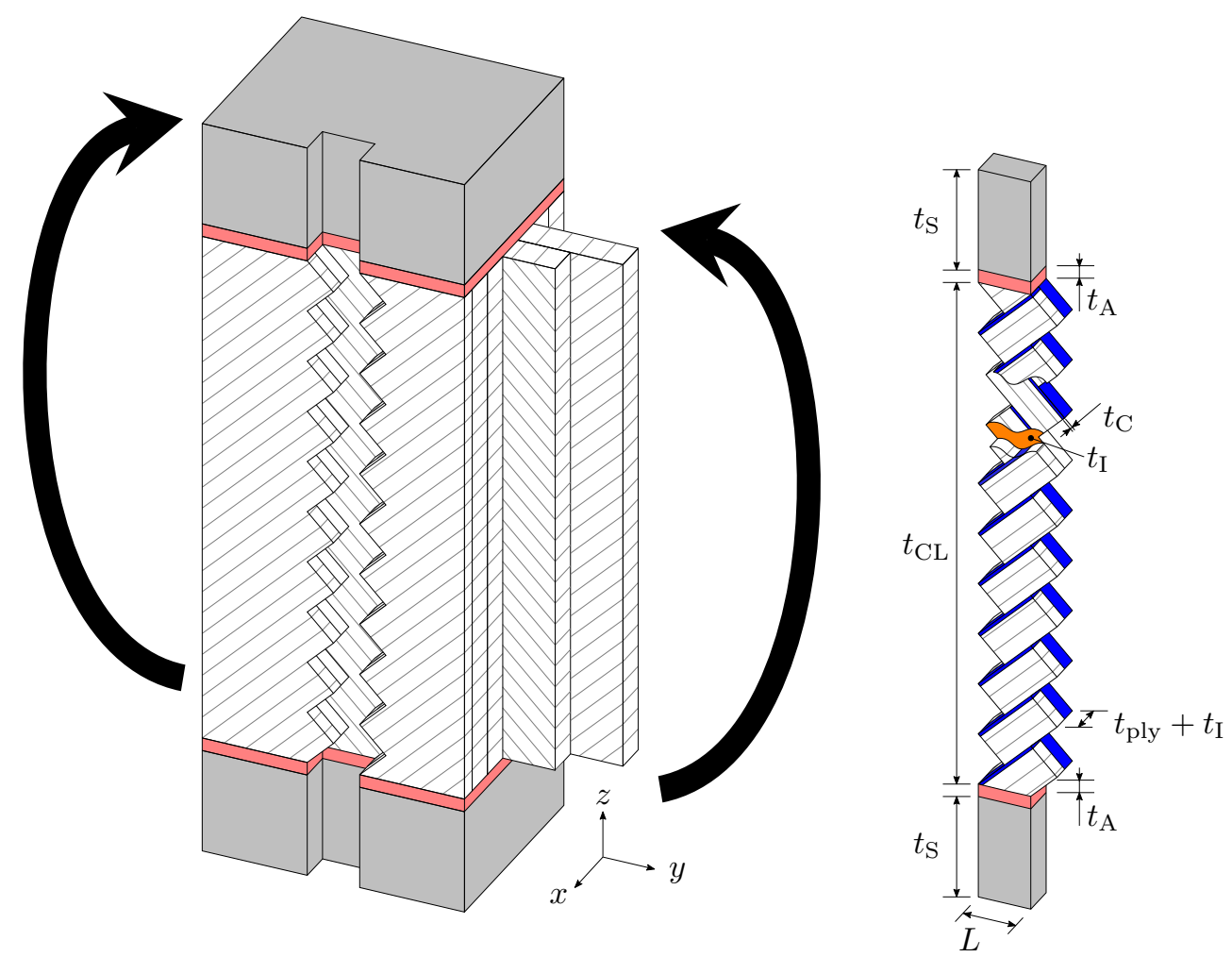

Figure 3: The damage diffusion in the H/CL unit (left) was studied using a parametric unit cell FE model (right).

boundary conditions. This is why the model in Figure 3 has an original zigzag shape; the boundary conditions will be detailed later in this section.

Additionally, in the middle layer, only half the thickness of the $+45^{\circ}$ and $-45^{\circ}$ plies was included in the model due to its periodicity. An interface with thickness $t_{\mathrm{I}}$ (Table 2) was also modelled between the $\pm 45^{\circ}$ plies to allow for debonding and subsequent frictional sliding of the plies using an elasto-plastic constitutive law with linear softening [9].

Table 2: Geometric parameters of the unit cell FE model. Various crack densities relating to different model lengths $L$ were studied for the H/CL unit.

\begin{tabular}{cccccccc}
\hline & $\begin{array}{c}t_{\mathrm{S}} \\
{[\mathrm{mm}]}\end{array}$ & $\begin{array}{c}t_{\mathrm{CL}} \\
{[\mathrm{mm}]}\end{array}$ & $\begin{array}{c}t_{\mathrm{A}} \\
{[\mathrm{mm}]}\end{array}$ & $\begin{array}{c}t_{\mathrm{C}} \\
{[\mathrm{mm}]}\end{array}$ & $\begin{array}{c}t_{\mathrm{I}} \\
{[\mathrm{mm}]}\end{array}$ & $\begin{array}{c}t_{\mathrm{ply}} \\
{[\mathrm{mm}]}\end{array}$ & $\begin{array}{c}L \\
{[\mathrm{~mm}]}\end{array}$ \\
\hline $\mathrm{H} / \mathrm{CL}-\mathrm{Al}$ & 0.40 & 2 & 0.05 & 0.001 & 0.001 & 0.125 & $0.1,0.2,0.4$ \\
$\mathrm{H} / \mathrm{CL}-\mathrm{Ti}$ & 0.05 & 2 & 0.05 & 0.001 & 0.001 & 0.125 & $0.1,0.2,0.4$ \\
\hline
\end{tabular}


The CFRP in the middle layer was modelled as having non-linear shear behaviour in the local 12-direction following the Ramberg-Osgood relationship and was subsequently allowed to fail in shear using anisotropic plasticity with linear softening. The CFRP was assumed to be linear-elastic with transverse isotropy in the other directions.

The metal layers were modelled as an elastic-plastic material with linear hardening

where $R$ is the radius of curvature, $y$ is the distance from the bending axis (Figure 4 ) and $\kappa$ is the curvature. The displacements in the $z$-direction on the left and right 
Table 3: Material properties used in the FE model. The subscript 1 denotes the fibre direction and subscripts 2 and 3 denote the transverse directions. $E_{i j}$ is the elastic modulus, $G_{i j}$ is the shear modulus and $\nu_{i j}$ is the Poisson's ratio. $k$ is the elastic stiffness of the cohesive law and is assumed to be the same for all Modes. $\tau_{\mathrm{I}}, \tau_{\mathrm{II}}$ and $\tau_{\mathrm{III}}$ are the strengths for Mode I, II and III of the prepreg, respectively, and $G_{\text {Ic }}, G_{\text {IIc }}$ and $G_{\text {IIIc }}$ are the corresponding critical energy release rates. $\alpha$ is the exponent of the mixed-mode power law, $K$ and $n$ are constants that define non-linearity for the shear behaviour, $\sigma^{\mathrm{y}}$ is the yield strength, $\sigma^{\mathrm{u}}$ is the ultimate strength and $\varepsilon^{\mathrm{f}}$ is the strain to failure.

\begin{tabular}{|c|c|c|c|c|c|c|c|c|c|}
\hline \multicolumn{3}{|c|}{ Prepreg } & \multicolumn{3}{|c|}{ Prepreg } & \multicolumn{2}{|c|}{ Metal } & \multirow{2}{*}{$\frac{\mathrm{Al}}{73.1^{[17]}}$} & \multirow{2}{*}{$\frac{\mathrm{Ti}}{105^{[18]}}$} \\
\hline$E_{11}$ & $\mathrm{GPa}$ & $164.0^{[15]}$ & $\tau_{\mathrm{I}}$ & $\mathrm{MPa}$ & $50^{[16]}$ & $E$ & $\mathrm{GPa}$ & & \\
\hline$E_{22}$ & $\mathrm{GPa}$ & $12.0^{[15]}$ & $\tau_{\mathrm{II}}$ & $\mathrm{MPa}$ & $80^{[16]}$ & $\nu$ & - & $0.33^{[17]}$ & $0.34^{[18]}$ \\
\hline$E_{33}$ & GPa & $12.0^{*}$ & $\tau_{\text {III }}$ & $\mathrm{MPa}$ & $80^{*}$ & $\sigma^{\mathrm{y}}$ & $\mathrm{MPa}$ & $270^{[17]}$ & $275^{[18]}$ \\
\hline$G_{12}$ & $\mathrm{GPa}$ & $4.6^{\dagger}$ & $G_{\text {Ic }}$ & $\mathrm{kJ} / \mathrm{m}^{2}$ & $0.3^{\ddagger}$ & $\sigma^{\mathrm{u}}$ & $\mathrm{MPa}$ & $405^{[17]}$ & $345^{[18]}$ \\
\hline$G_{13}$ & $\mathrm{GPa}$ & $4.6^{*}$ & $G_{\text {IIc }}$ & $\mathrm{kJ} / \mathrm{m}^{2}$ & $1.0^{[19]}$ & $\varepsilon^{f}$ & $\%$ & $12^{[17]}$ & $20^{[18]}$ \\
\hline$G_{23}$ & $\mathrm{GPa}$ & $4.3^{*}$ & $G_{\text {IIIc }}$ & $\mathrm{kJ} / \mathrm{m}^{2}$ & $1.0^{*}$ & & & & \\
\hline$\nu_{12}$ & - & $0.3^{[20]}$ & $\tau_{\mu}$ & $\mathrm{MPa}$ & $10^{[19]}$ & Ad & sive & & \\
\hline$\nu_{13}$ & - & $0.3^{*}$ & $\alpha$ & - & $1.0^{\dagger}$ & $E$ & $\mathrm{GPa}$ & 2.8 & \\
\hline$\nu_{23}$ & - & $0.4^{\dagger}$ & $K$ & $\mathrm{MPa}$ & $258.0^{[22]}$ & $\nu$ & - & 0.3 & \\
\hline$k$ & $\frac{\mathrm{MPa}}{\mathrm{mm}}$ & $4.67 \cdot 10^{6[23]}$ & $n$ & - & $0.212^{[22]}$ & $\sigma^{\mathrm{y}}$ & $\mathrm{MPa}$ & & $2^{\dagger}$ \\
\hline
\end{tabular}

* Assuming transverse isotropy

$\dagger$ Assumed based on typical values in the literature for similar material systems

$\ddagger$ Based on $[24]$

boundaries, $u_{3}^{\mathrm{L}}$ and $u_{3}^{\mathrm{R}}$, can thus be written as:

$$
\begin{aligned}
& u_{3}^{\mathrm{L}}(x, z)=\bar{u}_{3}^{\mathrm{L}}+\frac{1}{2} \kappa\left(y^{\mathrm{L}}\right)^{2}+\tilde{u}_{3}(x, z), \\
& u_{3}^{\mathrm{R}}(x, z)=\bar{u}_{3}^{\mathrm{R}}+\frac{1}{2} \kappa\left(y^{\mathrm{R}}\right)^{2}+\tilde{u}_{3}(x, z),
\end{aligned}
$$

where $y^{\mathrm{L}}$ and $y^{\mathrm{R}}$ are the distances of the left and right boundaries from the bending axis, $\bar{u}_{3}^{\mathrm{L}}$ and $\bar{u}_{3}^{\mathrm{R}}$ are displacements due to eventual rigid body motion of the face and $\tilde{u}_{3}(x, z)$ is the warping field (fluctuation terms). Subtracting Equation (2) from Equation (3) leads to

$$
u_{3}^{\mathrm{R}}(x, z)-u_{3}^{\mathrm{L}}(x, z)=\bar{u}_{3}^{\mathrm{R}}-\bar{u}_{3}^{\mathrm{L}}+\frac{1}{2}\left[\left(y^{\mathrm{R}}\right)^{2}-\left(y^{\mathrm{L}}\right)^{2}\right] \kappa .
$$

Equation (4) defines the periodic boundary conditions for $u_{3}$ on the left and right zigzag-shaped faces under bending. The periodic boundary conditions for the $u_{1}$ and 


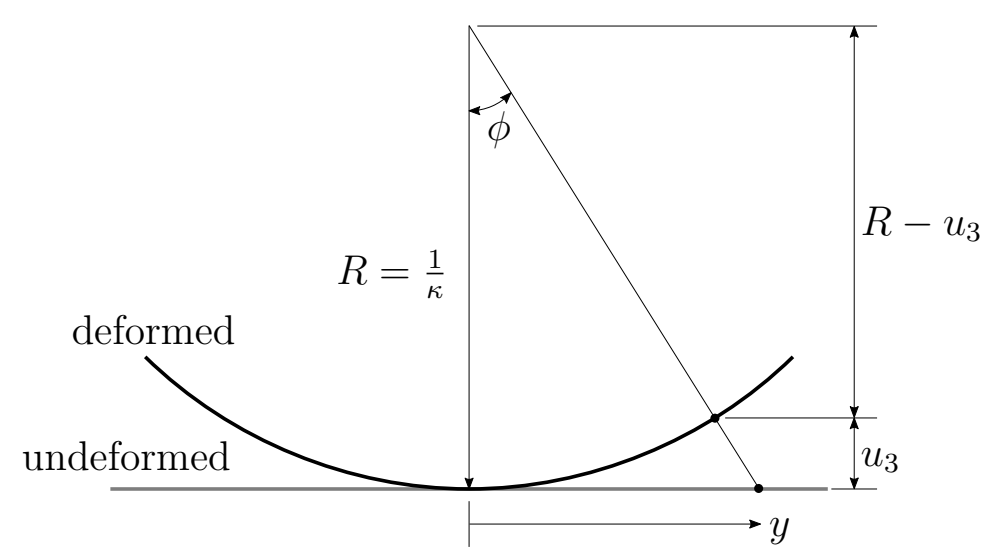

Figure 4: The displacement $u_{3}$ of a beam in bending can be determined based on the angle, $\phi$, and coordinate $y . R$ is the radius of curvature and $\kappa$ is the curvature.

$u_{2}$ displacements are the same as if the faces were flat [9]. In the FE environment, the bending boundary conditions were implemented using a master node $\mathrm{M}_{1}$ :

$$
\begin{aligned}
u_{1}^{\mathrm{R}}(x, z)-u_{1}^{\mathrm{L}}(x, z) & =u_{1}^{\mathrm{M}_{1}} \\
u_{2}^{\mathrm{R}}(x, z)-u_{2}^{\mathrm{L}}(x, z) & =u_{2}^{\mathrm{M}_{1}}-z L u_{4}^{\mathrm{M}_{1}} \\
u_{3}^{\mathrm{R}}(x, z)-u_{3}^{\mathrm{L}}(x, z) & =u_{3}^{\mathrm{M}_{1}}+\frac{1}{2}\left[\left(y^{\mathrm{R}}\right)^{2}-\left(y^{\mathrm{L}}\right)^{2}\right] u_{4}^{\mathrm{M}_{1}},
\end{aligned}
$$

where $u_{i}^{\mathrm{R}}$ and $u_{i}^{\mathrm{L}}$ are the displacements $i$ on the right and left boundaries, respectively, $z$ is the distance from the neutral axis, $L$ is the length of the model and $u_{i}^{\mathrm{M}_{1}}$ is the degree of freedom $i$ of the master node $\mathrm{M}_{1}$.

The bending was applied by giving $u_{4}^{\mathrm{M}_{1}}$ a displacement corresponding to a desired curvature while the degrees of freedom 1, 2 and 3 were left free. A symmetry boundary condition allowing Poisson's effect [9] was applied on the front and back boundaries:

$$
\begin{aligned}
& u_{1}^{\mathrm{F}}(y, z)=0, \\
& u_{1}^{\mathrm{B}}(y, z)=u_{1}^{\mathrm{M}_{2}}
\end{aligned}
$$

where $u_{1}^{\mathrm{F}}$ and $u_{1}^{\mathrm{B}}$ are the displacement on the front and back boundaries, respectively, and $u_{1}^{\mathrm{M}_{2}}$ is the degree of freedom 1 of the master node $\mathrm{M}_{2}$, which was left free (to allow 
for Poisson's effect); the components 2 and 3 of the displacements on the front and back faces were left free.

\subsubsection{Numerical results}

The results of the FE analysis are summarised in Figure 5. Figures 5(a) and (b) show the normalised moment vs curvature graphs of the H/CL-Al and H/CL-Ti configurations, respectively. The numerical simulations predict a nearly identical mechanical response for all investigated crack densities, suggesting that the splits do not open significantly and hence our results are not restricted to the crack densities considered. This is also seen in Figure 5(c), showing that the energy dissipation per unit volume in the bulk of the CFRP is diffuse and not significantly affected by the cohesive regions. A detailed view of the model (showing also the mesh size used in the analysis) enclosed in Figure 5(c) further shows diffuse damage and fine shear bands in the CFRP. Figure 5(d) shows that the energy dissipation per unit area in the cohesive elements is limited and concentrated on a small area on the tension side. It can therefore be concluded from the numerical simulations that the microstructures proposed in Section 2.1 should promote diffuse damage and are suitable for prototyping.

\subsection{Prototyping}

We prototyped the H/CL/QI microstructures based on a procedure outlined in the literature $[9,11]$. In addition, we prototyped specimens corresponding to the H/CL unit in order to verify the numerical results.

To manufacture the crossed-lamellar CFRP layer, a laminate with a nominal thickness of $12 \mathrm{~mm}$ and a symmetric lay-up sequence $\left[+45^{\circ} /-45^{\circ}\right]_{24 \mathrm{~S}}$ was cured according to the manufacturer's instructions and cut into $2 \mathrm{~mm}$ wide slices using a water jet cutter. The slices were then rotated so that the fibre orientation angle was now with respect to the thickness direction. A quasi-isotropic laminate with a lay-up sequence $\left[0^{\circ} /+45^{\circ} / 90^{\circ} /-45^{\circ}\right]_{\mathrm{S}}$ and a nominal thickness of $1 \mathrm{~mm}$ was also manufactured and subsequently cut into $12 \mathrm{~mm}$ x $150 \mathrm{~mm}$ pieces. 


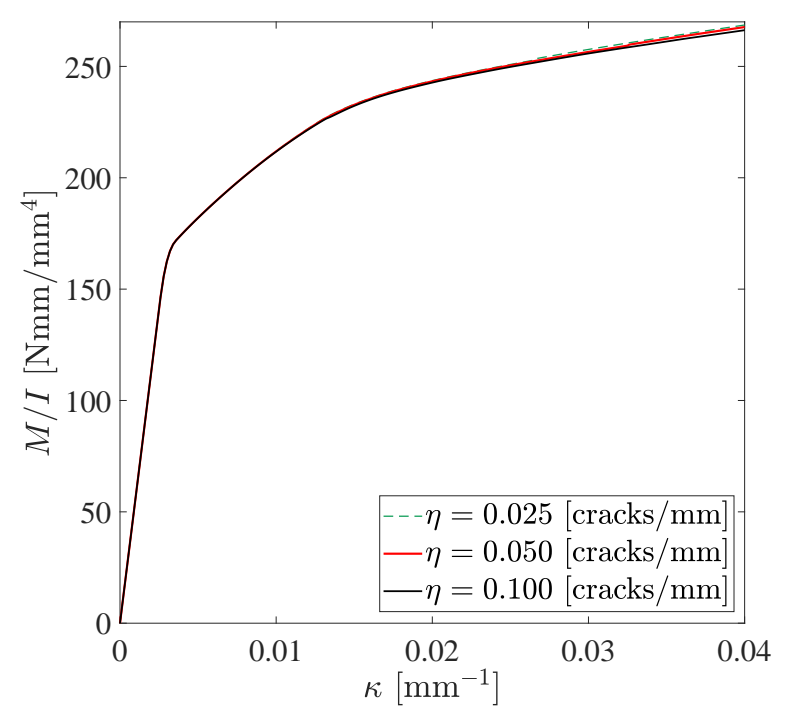

(a) H/CL-Al

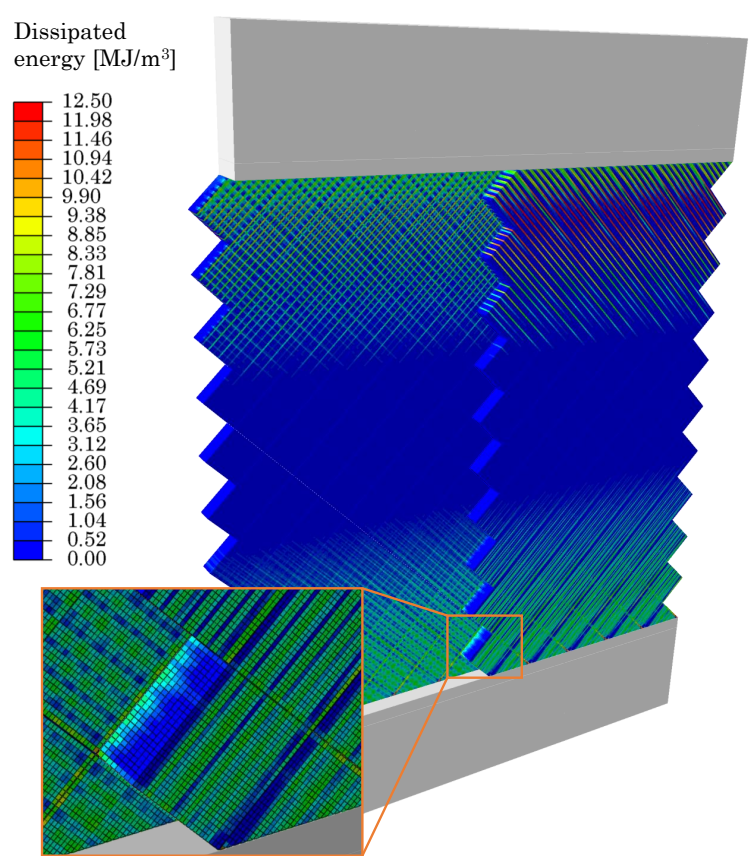

(c) $\mathrm{H} / \mathrm{CL}-\mathrm{Al}, \eta=0.05 \mathrm{cracks} / \mathrm{mm}$

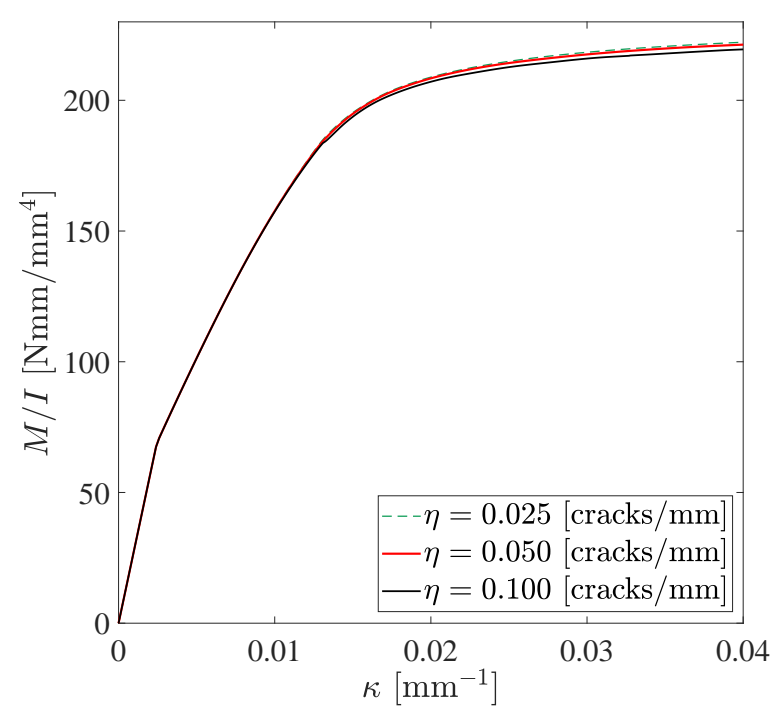

(b) H/CL-Ti

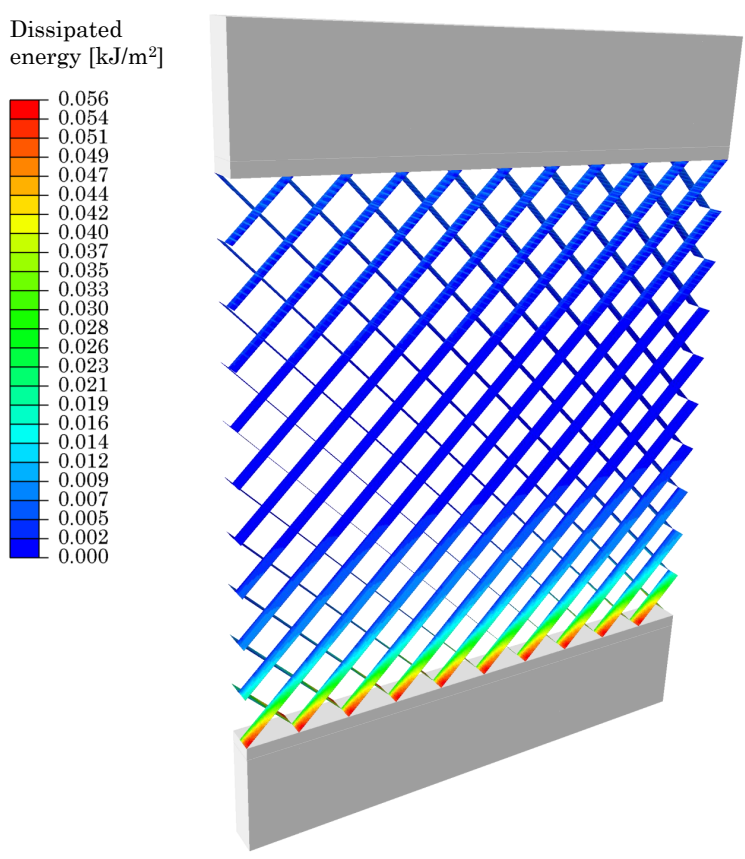

(d) $\mathrm{H} / \mathrm{CL}-\mathrm{Al}, \eta=0.05 \mathrm{cracks} / \mathrm{mm}$

Figure 5: The H/CL unit shows similar mechanical behaviour for the (a) H/CL-Al and (b) H/CL-Ti units with different prescribed crack densities; (c) the energy dissipation per unit volume in the bulk of the CFRP is diffused, with fine shear bands seen in the detailed view of the model, while (d) the energy dissipation per unit area in the cohesive elements is low and concentrated on the tension side. 
The surface of the metal was pre-treated for better adhesion. In this process, the aluminium was first grit-blasted and etched in chromic acid according to the guidelines by Forest Product Laboratory [25]. The aluminium was submerged in $68^{\circ} \mathrm{C}$ acid

solution for 20 minutes and rinsed under running water for another 20 minutes.

The titanium was first etched in 15\% nitric acid for 15 minutes and rinsed with distilled water. It was then further etched in 3\% hydrofluoric acid solution for 30 seconds, rinsed with distilled water, subsequently anodised in $5 \mathrm{M}$ sodium hydroxide with 10-15 V electric current for 15 minutes, and finally rinsed under running water for 20 minutes.

The H/CL/QI microstructures and H/CL units illustrated in Figure 2 were constructed from these components and bonded using 3M ScotchWeld 9323 B/A toughened epoxy adhesive. After applying the adhesive, the microstructures were clamped and cured at $65^{\circ} \mathrm{C}$ for two hours to accelerate the strength build-up.

\subsection{Testing}

We tested three specimens of each manufactured configuration (hence four types of specimens) in a four-point bending configuration as schematically illustrated in Figure 6. The dimensions of the test set-up and the average dimensions of the specimens are given in Table 4.

The testes were carried out using an Instron machine with a $50 \mathrm{kN}$ load cell. The specimens were loaded at a displacement rate of $1 \mathrm{~mm} / \mathrm{min}$ and the data was recorded with a rate of $10 \mathrm{~Hz}$. The displacements were read from the built-in extensometer and the deformation of the specimens was monitored by capturing images every ten seconds using a high-resolution digital camera. The displacement was reversed before the specimen touched the base of the test rig. 


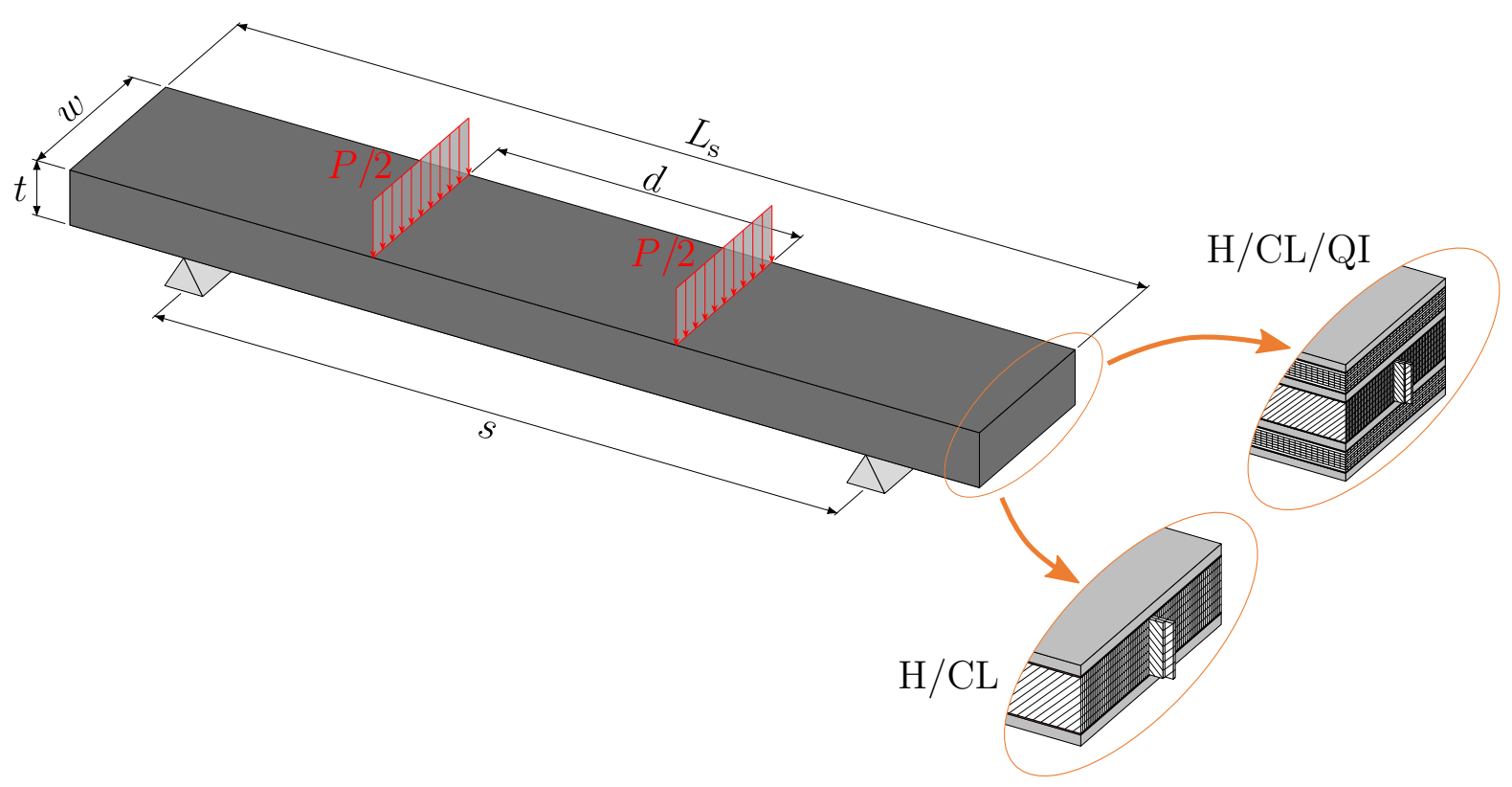

Figure 6: Sketch of the test set-up of the four-point bending test showing the dimensions and the testing orientation of the specimens.

Table 4: Dimensions of the tested specimens.

\begin{tabular}{cccccc}
\hline Specimen & $d[\mathrm{~mm}]$ & $s[\mathrm{~mm}]$ & $t[\mathrm{~mm}]$ & $w[\mathrm{~mm}]$ & $L_{\mathrm{s}}[\mathrm{mm}]$ \\
\hline H/CL-Al & 32 & 90 & 3.0 & 11.8 & 150 \\
H/CL-Ti & 32 & 90 & 2.2 & 11.9 & 148 \\
H/CL/QI-Al & 30 & 110 & 5.8 & 11.6 & 150 \\
H/CL/QI-Ti & 30 & 110 & 4.3 & 11.4 & 149 \\
\hline
\end{tabular}

\section{Results}

Figures 7 and 8 show selected images of the H/CL and H/CL/QI specimens, respectively, during testing, showing the failure sequence of the specimens. The mechanical response of all tested specimens is given in Figure 9, and the instances corresponding to Figures 7 and 8 are annotated in the load vs displacement graphs in Figure 10, where the load, $P$, is normalised by the second moment of area, $I$. The reader is referred to the supplementary material of this article for the full deformation sequence of the test specimens. 


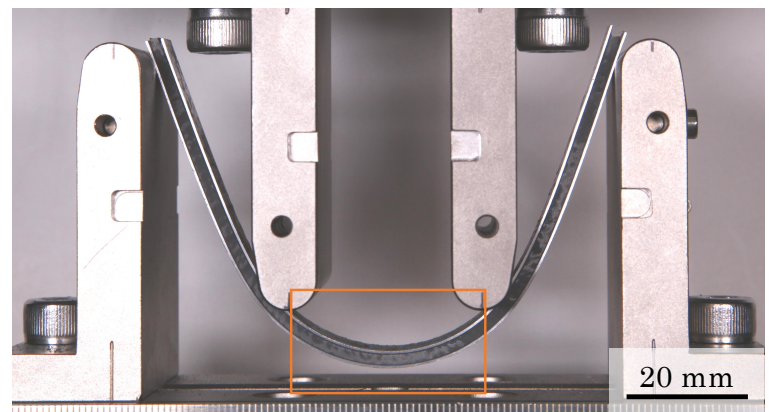

(a) Maximum displacement, $\mathrm{H} / \mathrm{CL}-\mathrm{Al}$

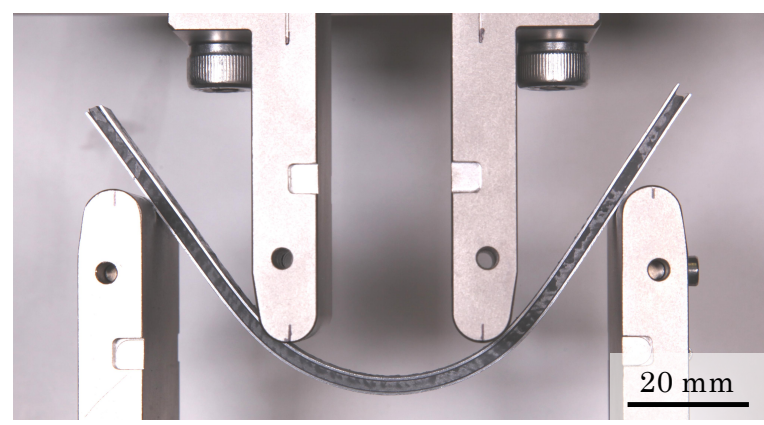

(c) End of test, H/CL-Al

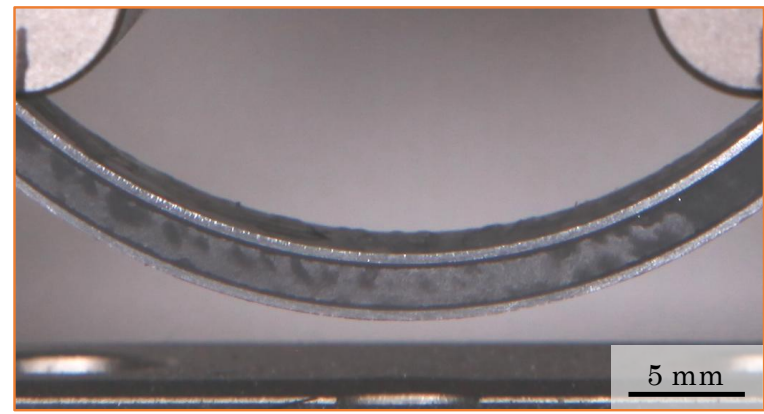

(e) Close-up at maximum displacement, H/CL-Al

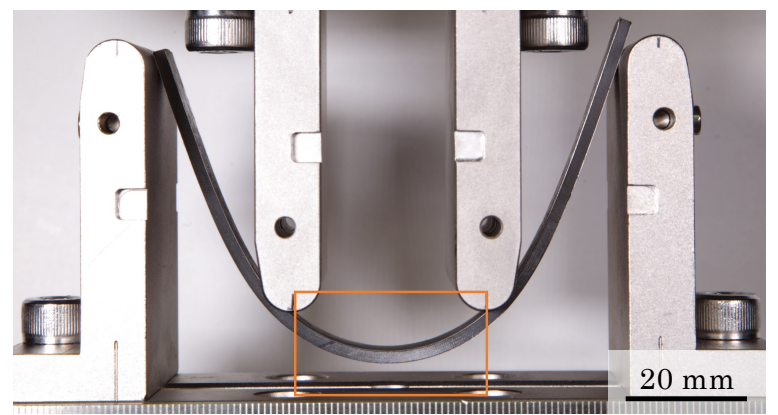

(b) Maximum displacement, H/CL-Ti

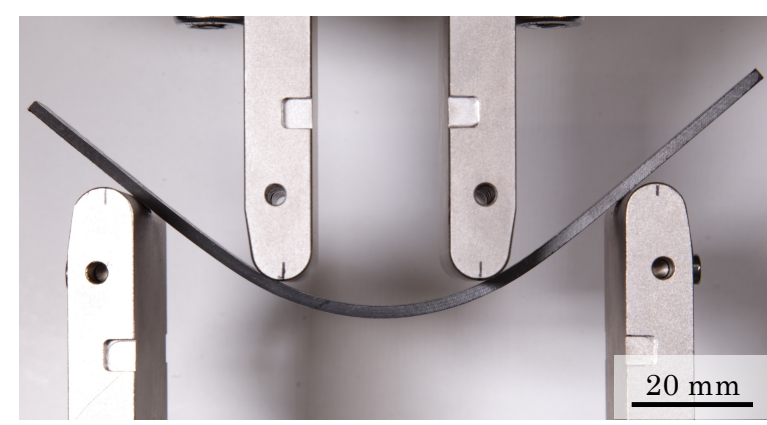

(d) End of test, H/CL-Ti

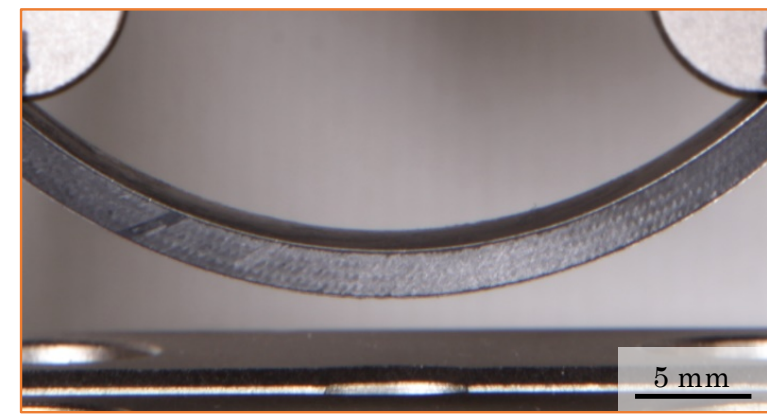

(f) Close-up at maximum displacement, H/CL-Ti

Figure 7: Both H/CL units preserved their structural integrity up to the maximum displacement allowed by the rig, and exhibited significant residual curvature after the load was removed. The images correspond to the annotated instances in Figure 10(a).

Figure 7 shows the deformation sequence of the tested H/CL units. Figures $7(\mathrm{a})$ and (b) show the H/CL-Al and H/CL-Ti specimens at the maximum deflection before the displacement was reversed, while the specimens at the end of the test (zero load) are shown in Figures 7(c) and (d). Figures 7(e) and (f) show a close-up of the specimens at maximum deflection. The instances corresponding to the images are annotated in Figure 10(a). 


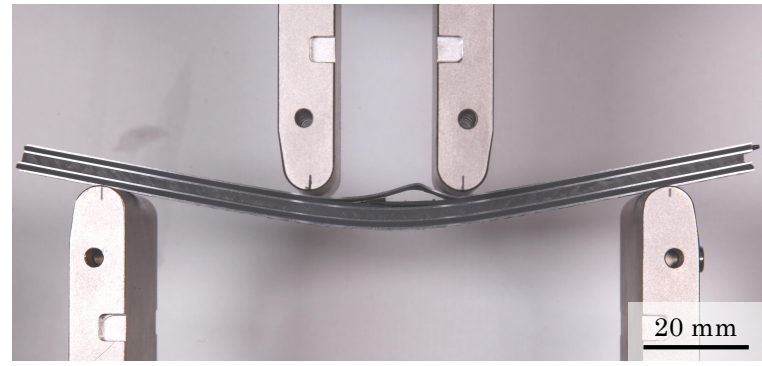

(a) $\delta=7.0 \mathrm{~mm}, \mathrm{H} / \mathrm{CL} / \mathrm{QI}-\mathrm{Al}$

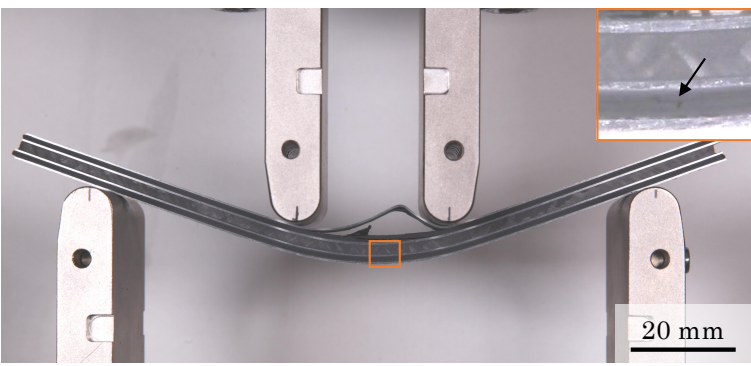

(c) $\delta=12.8 \mathrm{~mm}, \mathrm{H} / \mathrm{CL} / \mathrm{QI}-\mathrm{Al}$

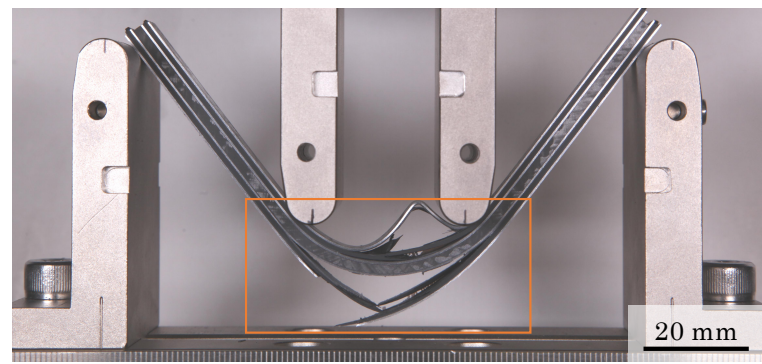

(e) $\delta=42.1 \mathrm{~mm}, \mathrm{H} / \mathrm{CL} / \mathrm{QI}-\mathrm{Al}$

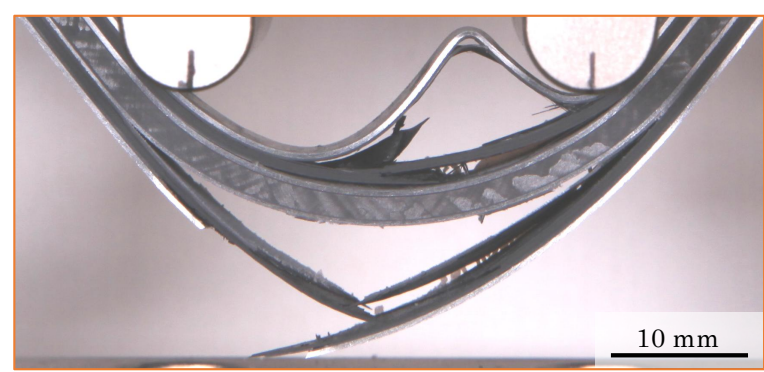

(g) $\delta=42.1 \mathrm{~mm}, \mathrm{H} / \mathrm{CL} / \mathrm{QI}-\mathrm{Al}$

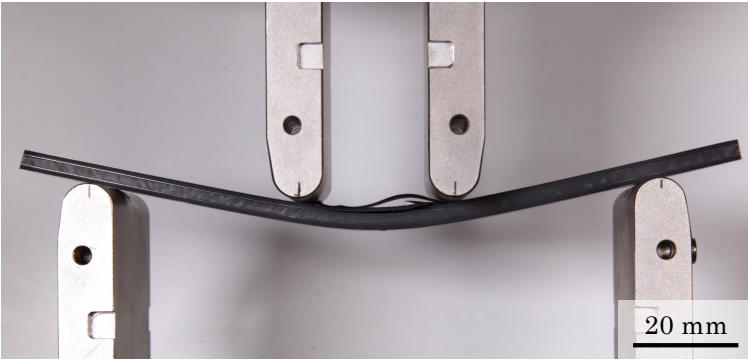

(b) $\delta=8.0 \mathrm{~mm}, \mathrm{H} / \mathrm{CL} / \mathrm{QI}-\mathrm{Ti}$

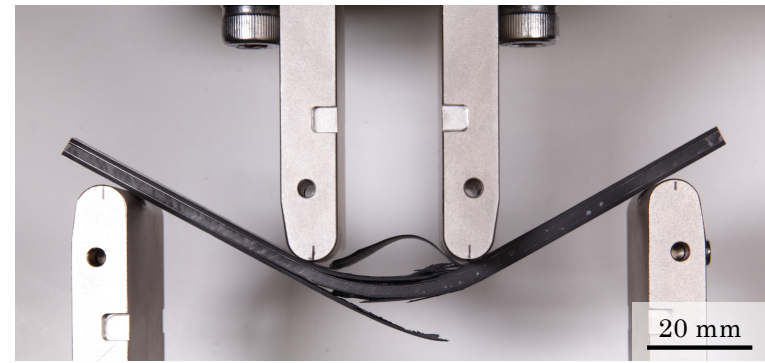

(d) $\delta=19.7 \mathrm{~mm}, \mathrm{H} / \mathrm{CL} / \mathrm{QI}-\mathrm{Ti}$

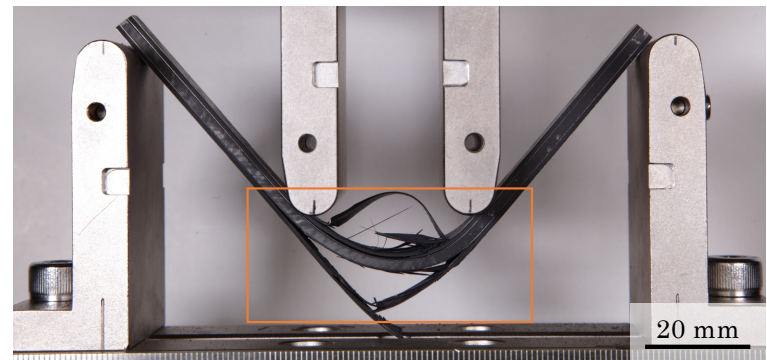

(f) $\delta=39.0 \mathrm{~mm}, \mathrm{H} / \mathrm{CL} / \mathrm{QI}-\mathrm{Ti}$

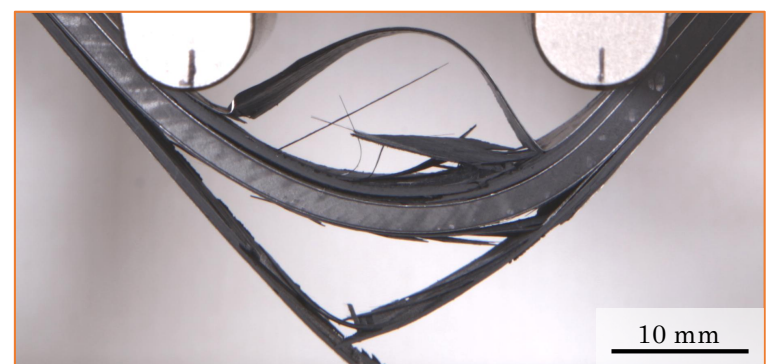

(h) $\delta=39.0 \mathrm{~mm}, \mathrm{H} / \mathrm{CL} / \mathrm{QI}-\mathrm{Ti}$

Figure 8: During progressive failure of the H/CL/QI microstructure, the H/QI units fail, eventually, but the H/CL unit holds the specimen together without discrete damage visible. The images correspond to the annotated instances in Figure 10(b). Figures 8(g) and (h) show close-ups of the enclosed areas in Figures 8(e) and (f). 


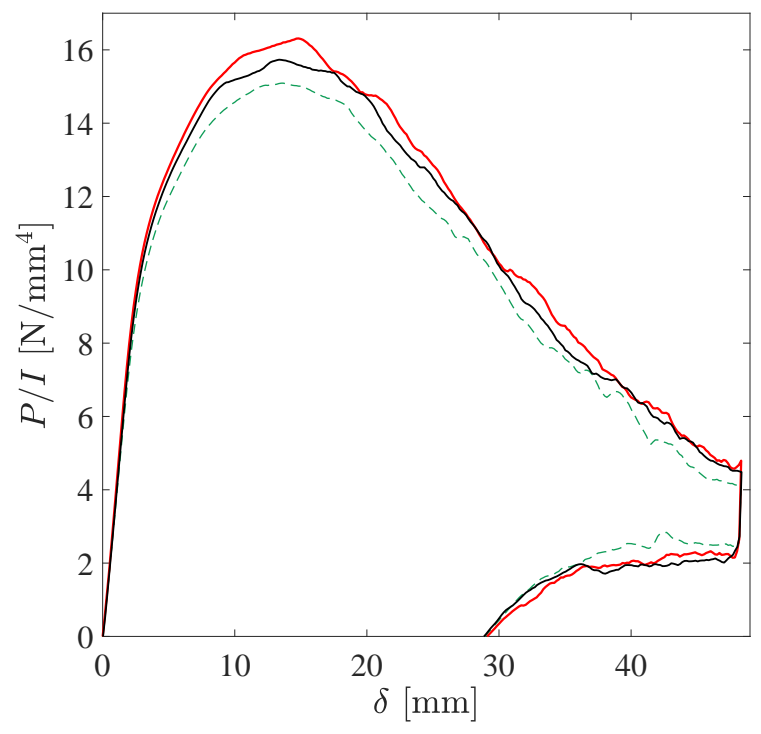

(a) $\mathrm{H} / \mathrm{CL}-\mathrm{Al}$

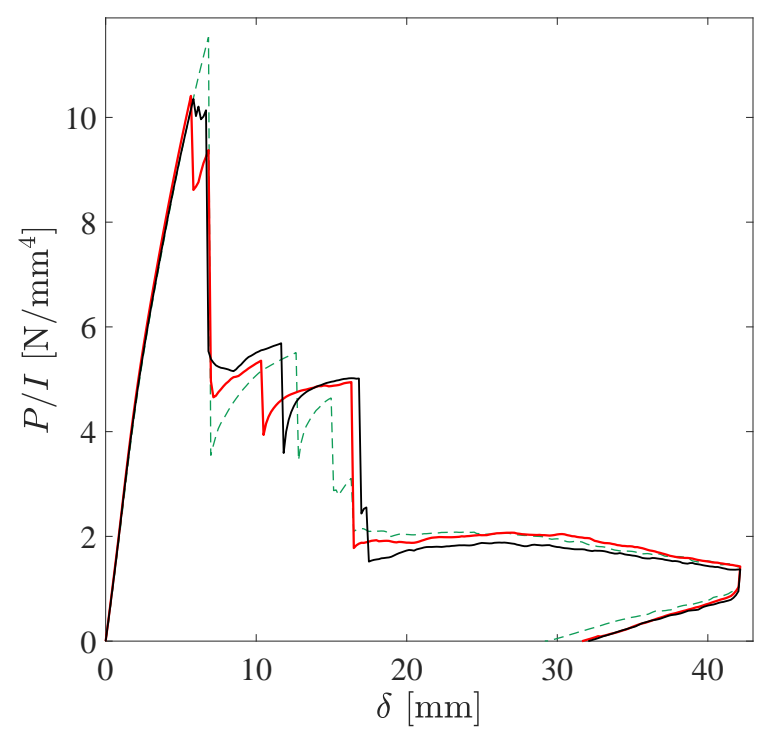

(c) $\mathrm{H} / \mathrm{CL} / \mathrm{QI}-\mathrm{Al}$

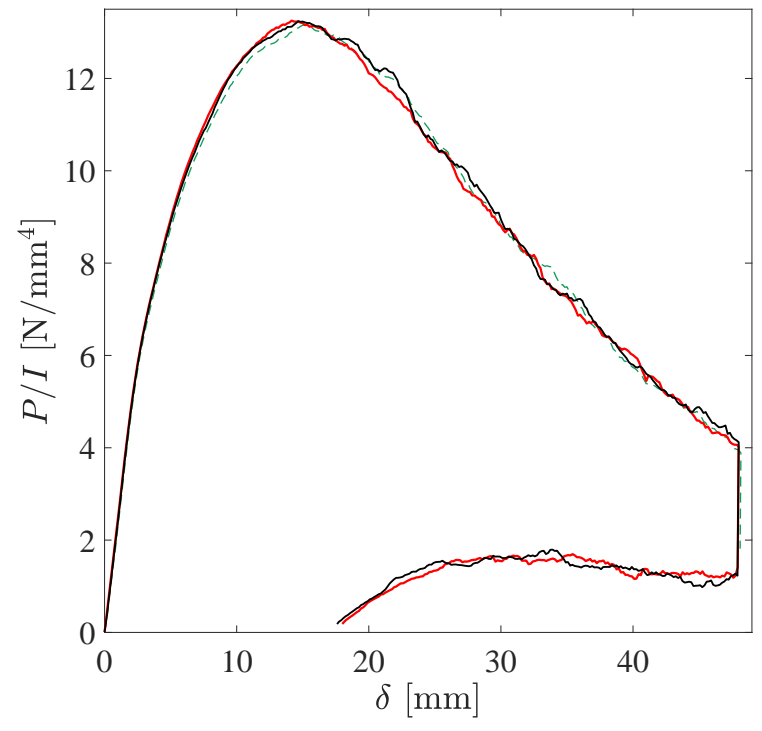

(b) H/CL-Ti

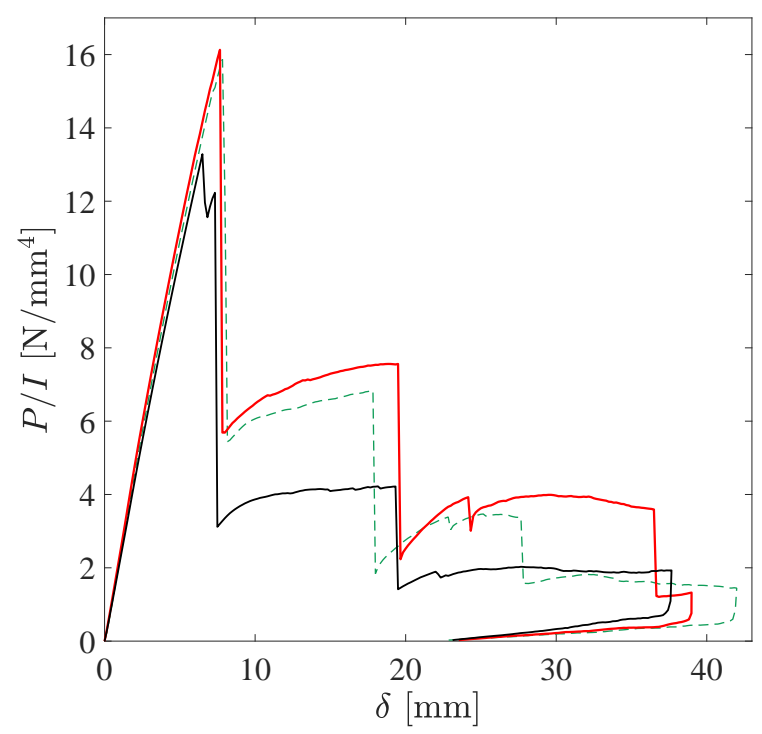

(d) H/CL/QI-Ti

Figure 9: The mechanical response did not vary significantly between the three repetitions carried out for each tested configuration.

Figure 8 shows the deformation sequence of the tested H/CL/QI microstructures. Figures 8(a) and (b) show the H/CL/QI-Al and H/CL/QI-Ti specimens after the first load drop, and Figures 8(c) and (d) show the specimens at a later stage of the test after a smaller load drop. Figures 8(e) and (f) show the specimens at the maximum deflection, with a more detailed view given in Figures $8(\mathrm{~g})$ and (h). Figure 10(b) shows 
the corresponding instances in the load vs displacement curve.

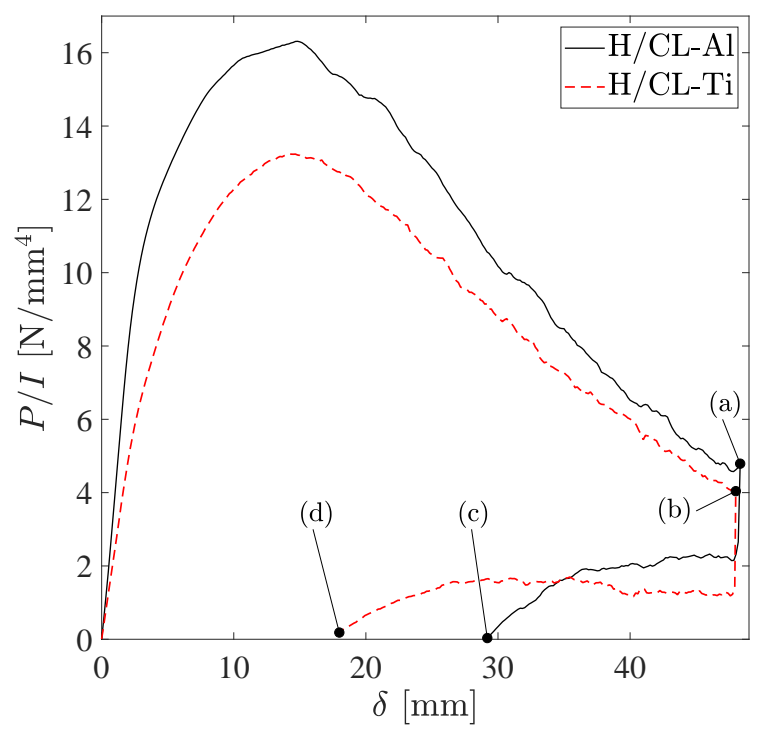

(a) H/CL unit

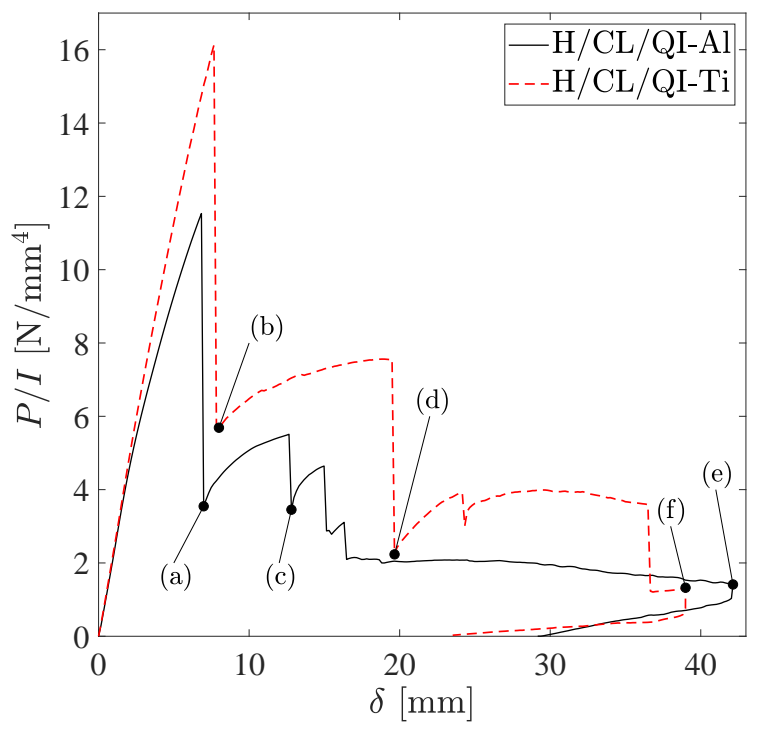

(b) $\mathrm{H} / \mathrm{CL} / \mathrm{QI}$ microstructure

Figure 10: (a) The H/CL unit deforms in a stable manner; (b) the H/CL/QI microstructure fails progressively without fully losing its load-carrying capacity. 


\section{Discussion}

\subsection{Mechanical behaviour of the $H / C L$ unit}

\subsubsection{Experimental results}

The H/CL units with different skin materials $(0.4 \mathrm{~mm}$ thick aluminium and $0.05 \mathrm{~mm}$ thick titanium) exhibit qualitatively similar mechanical behaviour (Figure 10(a)). The microstructures deform stably and retain their structural integrity while very significantly bent (Figures 7(a) and (b)). The microstructures spring back upon unloading, with the springback being greater for the H/CL-Ti microstructure than for the H/CL-Al microstructure (Figures $7(\mathrm{c})$ and $(\mathrm{d})$ ).

No macroscopic damage is visible on the surface of the H/CL microstructures (Figures $7(\mathrm{e})$ and (f)). The absence of discrete splits suggests that the damage is governed by plastic shear deformation in the matrix and yielding of the metal skins.

The H/CL units undergo large deformations without breaking. Three-point bend tests on hybrid composites in the literature [11] exhibit similar behaviour and show that configurations without crossed-lamellar layers are more brittle and fail at smaller curvatures than crossed-lamellar composites.

\subsubsection{Comparison with numerical results}

The load vs displacement response of the H/CL units was converted to moment vs curvature graphs in order to compare the mechanical response of the microstructures with the numerical results. The curvature of the specimens was measured from the images taken during the test. The applied bending moment was evaluated based on the following assumptions (see Figure 11):

- the load drop when the displacement rate is reversed $(\delta \approx 48 \mathrm{~mm}$ in Figure $10(\mathrm{a}))$ is caused by changing direction of frictional forces;

- during the instant at which the displacement rate is reversed, and at which a constant displacement is applied, the deformed shape of the specimen does not change; as a result, 
- the contact angle between the load pin and the specimen, $\theta_{\mathrm{L}}$, and between the support pin and the specimen, $\theta_{\mathrm{S}}$, does not change during the load drop; - the curvature and hence applied moment is constant during the load drop.

First, the friction coefficient was solved from the vertical force equilibrium and the moment equilibrium around the load pin before and after the load drop (Figures 10(a) and 11). After solving the friction coefficients (Table 5), the load recorded during the test was converted to a moment according to the geometry of the problem from Figure 11. The contact angle $\theta_{\mathrm{S}}$ and the moment arms $u$ and $v$ were measured from the images taken during the test. The experimental and numerical normalised moment vs curvature graphs are shown in Figure 12.

The numerical results are within a reasonable agreement with the experimental results (Figure 12). The results match in the elastic region and at the early stages of softening. After that, the numerical results predict a stiffer response with a more gradual stiffness loss. The numerical results predict a plateau that is also observed

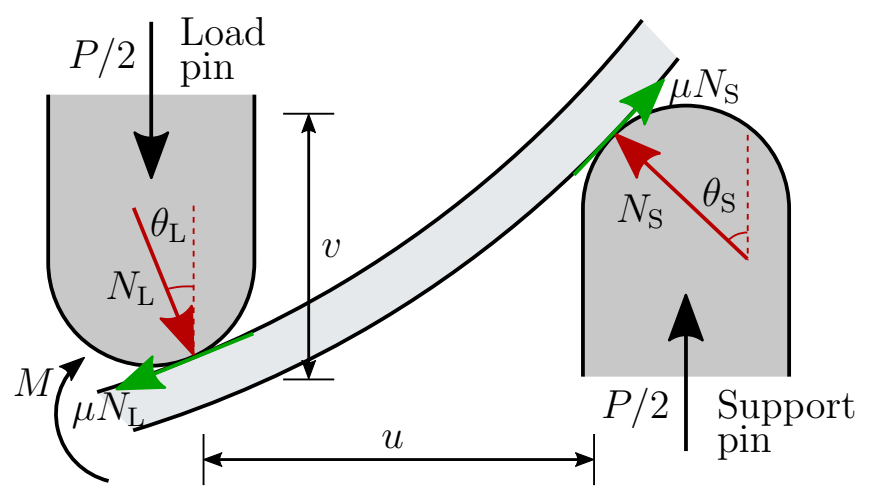

Figure 11: The loads and moment acting on the specimen when it is being loaded. $P$ is the load recorded by the load cell, $N$ is the normal force of the contact between the pins and the specimen, $\mu$ is the friction coefficient, $\theta$ is the contact angle, $M$ is the moment and $u$ and $v$ are the horizontal and vertical moment arms, respectively. The subscripts $\mathrm{L}$ and $\mathrm{S}$ denote the load and support pins.

Table 5: The friction coefficients between the specimen and the load and support pins obtained from the experimental results.

\begin{tabular}{ccc}
\hline & H/CL-Al & H/CL-Ti \\
\hline$\mu$ & 0.100 & 0.168 \\
\hline
\end{tabular}




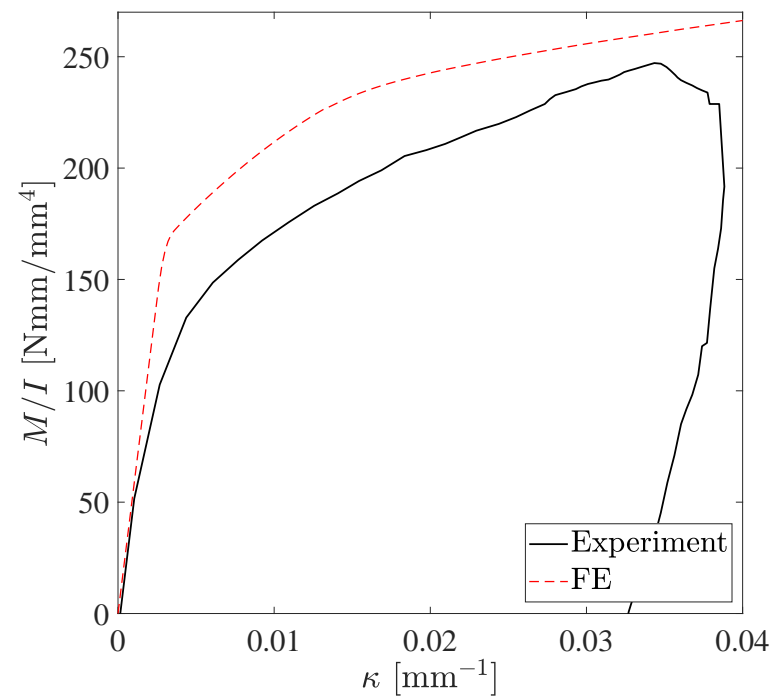

(a) Moment vs curvature, H/CL-Al

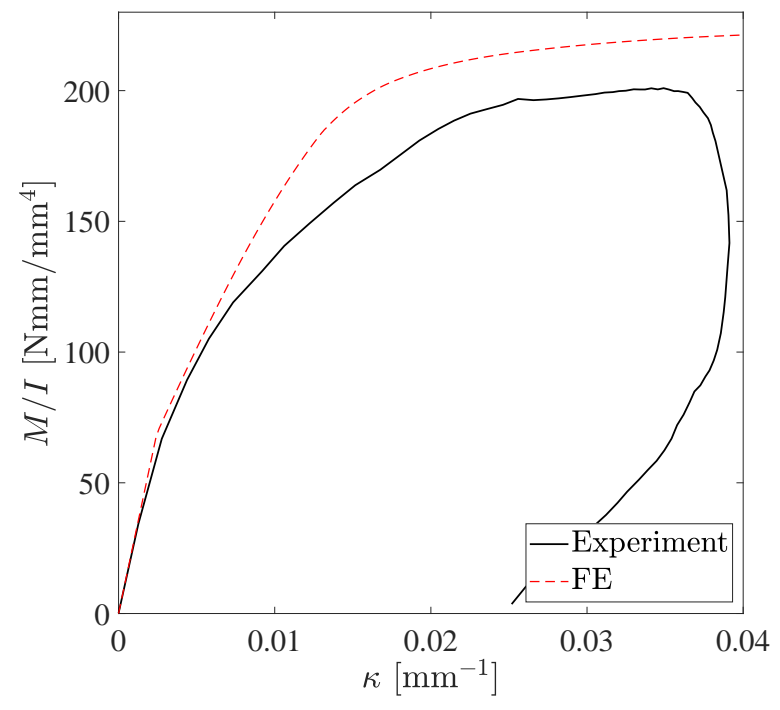

(b) Moment vs curvature, H/CL-Ti

Figure 12: The numerical results of the H/CL unit agree reasonable well with the experimental results.

in the experimental results. The small differences in the experimental and numerical results may be influenced by several factors, including the approximations during the load-to-moment conversion of the experimental results, and uncertainty in the material properties used in the Finite Element simulations.

No discrete splits were observed either in the experiments or in the simulations (Figures 5 and 7). This supports the notion that the damage in the crossed-lamellar CFRP is governed by plasticity in the matrix.

\subsection{Mechanical behaviour of the $H / C L / Q I$ microstructure}

In the $\mathrm{H} / \mathrm{CL} / \mathrm{QI}$ microstructures, the stiff $\mathrm{H} / \mathrm{QI}$ units are not able to accommodate the large deformations of the microstructure, leading to an unstable progressive failure of these units, while the H/CL unit is able to withstand the deformations, successfully retaining the specimen in one piece at the end of the test (Figures 8 and and 10(b)).

The failure sequence in the H/CL/QI-Al and H/CL/QI-Ti microstructures (with $0.4 \mathrm{~mm}$ and $0.05 \mathrm{~mm}$ thick metal sheets, respectively) is very similar. The H/QI unit on the compressive side fails first (Figures 8(a) and (b)), leading to a major load drop in the load vs displacement curves. During the load drop, the top metal layer buckles 
upwards and the quasi-isotropic CFRP delaminates at the $0^{\circ} / 45^{\circ}$ ply interface, followed by translaminar failure of the quasi-isotropic ply and delamination at the interface

- hybrid metal/crossed-lamellar microstructures with quasi-isotropic layers are stiff and strong, and also fail progressively because the crossed-lamellar layer prevents them from losing their structural integrity upon bending; 
- hybrid metal/crossed-lamellar units fail stably up to large curvatures;

- boundary conditions for pure bending on zigzag-shaped unit cells were derived and applied on a parametric FE model to study damage dissipation in hybrid metal/crossed-lamellar microstructures;

- the numerical results are in good agreement with the experimental results, showing that the hybrid metal/crossed-lamellar microstructures deform without discrete splits forming in the CFRP;

In summary, this paper demonstrated that crossed-lamellar microstructures in CFRP, combined with aerospace grade metals, maintain their structural integrity up to large deformations. In a microstructure with in-plane fibres, a crossed-lamellar unit can prevent penetration damage and loss of structural integrity, thus having significant implications for the use of these composites in containment structures (e.g. for blast and blade-off events).

\section{Acknowledgments}

The funding from the EPSRC under the grant EP/M002500/1 is gratefully acknowledged. The authors also acknowledge Dr Bamber Blackman, from the Department of Mechanical Engineering at Imperial College London, for his kind and helpful assistance with the surface treatment of the aluminium and titanium. The authors acknowledge Mr Qi Miao and Ms Maria Atienza Menendez, MSc and MEng students at Imperial College London, respectively, for their involvement in some of the experimental and numerical work, respectively. Finally, the authors acknowledge Dr John Alan Pascoe, from the Department of Aeronautics at Imperial College London, for his assistance with etching of the titanium and with testing of the hybrid titanium specimens. 


\section{References}

[1] P.-Y. Chen, J. McKittrick, and M. A. Meyers. Biological materials: functional adaptations and bioinspired designs. Progress in Materials Science, 57(8):1492$1704,2012$.

[2] X. W. Li, H. M. Ji, G. P. Zhang, and D. L. Chen. Mechanical properties of crossed-lamellar structures in biological shells: A review. Journal of the Mechanical Behavior of Biomedical Materials, 74:54-71, 2017.

[3] L. T. Kuhn-Spearing, H. Kessler, E. Chateau, R. Ballarini, A. H. Heuer, and S. M. Spearing. Fracture mechanisms of the Strombus gigas conch shell: implications for the design of brittle laminates. Journal of Materials Science, 31(24):6583-6594, 1996.

[4] Y. Liang, J. Zhao, L. Wang, and F.-M. Li. The relationship between mechanical

[6] C. L. Salinas, E. Escobar de Obaldia, C. Jeong, J. Hernandez, P. Zavattieri, and D. Kisalius. Enhanced toughening of the crossed lamellar structure revealed by nanoindentation. Journal of the Mechanical Behavior of Biomedical Materials, pages $1-11,2017$.

[7] R. Menig, M. H. Meyers, and K. S. Vecchio. Quasi-static and dynamic mechanical response of Strombus gigas (conch) shells. Materials Science and Engineering A, 297(1-2):203-211, 2001.

[8] X.-W. Su, D.-M. Zhang, and Heuer A. H. Tissue regeneration in the shell of the giant queen conch, Strombus gigas. Chemistry of Materials, 16(4):581-593, 2004. 
[9] R. Häsä and S.T. Pinho. Failure mechanisms of biological crossed-lamellar mi-

[15] Hexcel. http://www.hexcel.com/user_area/content_media/raw/HexPly_8552_eu_DataSheet.pdf, Accessed 29/09/2017.

[16] S. T. Pinho, R. Darvizeh, P. Robinson, C. Schuecker, and P. P. Camanho. Material

[17] MatWeb. Alcald aluminium 2024-T3. http://www.matweb.com/search/DataSheet .aspx?MatGUID=781ce4adb30c4d548320b0ab262a5d28, Accessed 01/04/2019. 
[18] Metalcor GmbH. Ti grade 2 datasheet. http://www.metalcor.de/en/datenblatt/122/, Accessed 02/03/2019.

[19] S. Pimenta and S. T. Pinho. An analytical model for the translaminar fracture toughness of fibre composites with stochastic quasi-fractal fracture surfaces. Journal of the Mechanics and Physics of Solids, 66:78-102, 2014.

[20] Hexcel. HexPly 8552 product data sheet, US version. http://www.hexcel.com/user_area/content_media/raw/HexPly_8552_us_DataSheet.pdf, Accessed 29/09/2017.

[21] J. Dogra. The development of a new compression test specimen design for thick laminate composites. PhD thesis, Imperial College London, UK, 2010.

[22] Y. He. Matrix-dominated constitutive laws for composite materials. PhD thesis, Georgia Institute of Technology, GA, USA, 2010.

[23] Dassault Systèmes. Abaus analysis user's guide. Abaqus 2016 online documentation, 2015.

[24] S. T. Pinho, P. Robinson, and L. Iannucci. Developing a four point bend specimen to measure the mode i intralaminar fracture toughness of unidirectional laminated composites. Composites Science and Technology, 69(7-8):1303-1309, 2009.

[25] G. W. Critchlow and D.M. Brewis. Review of surface pretreatments for aluminium alloys. International Journal of Adhesion and Adhesives, 16(4):255-275, 1996. 